\title{
Evolving Solutions in the Surgical Treatment of Isolated Pulmonary Valve Stenosis
}

Sonia B. Albanese ( $\nabla$ sonia.albanese@opbg.net)

Bambino Gesù Children's Hospital

Matteo Trezzi

Bambino Gesù Children's Hospital

Elena Pelliccione

Bambino Gesù Children's Hospital

Francesca Gatta

Bambino Gesù Children's Hospital

Alessia Del Pasqua

Bambino Gesù Children's Hospital

Giulio Calcagni

Bambino Gesù Children's Hospital

\section{Research Article}

Keywords: pulmonary valve stenosis, surgery, children

Posted Date: March 1st, 2021

DOI: https://doi.org/10.21203/rs.3.rs-244126/v1

License: (c) (i) This work is licensed under a Creative Commons Attribution 4.0 International License.

Read Full License

Version of Record: A version of this preprint was published at Journal of Cardiology and Cardiovascular Research on December 10th, 2021. See the published version at https://doi.org/10.37191/Mapsci-JCCR2(3)-044. 


\section{Abstract}

Background. Surgical treatment of isolated pulmonary valve stenosis in infants and children has evolved over the years, shifting from the original exclusive aim at lowering right ventricle pressure to the current concomitant focus on preserving pulmonary valve function. In our study, we sought to analyze the effect of such evolving philosophy on mid-term results.

Methods. 123 consecutive patients were treated in our center between 07/1983 and 03/2019. Mean age and weight were $3.0 \pm 0.36$ years and $16.6 \pm 1.7 \mathrm{~kg}$, respectively. Patients were categorized into 2 groups based on the onset of sparing valve techniques (1995). Short- and long-term mortality, freedom from reintervention on the right outflow tract, transvalvular mean pressure gradient decrease and pulmonary valve insufficiency were analyzed.

Results. Early mortality occurred exclusively before 1995 (Group 1, 3.76\%, p=ns). Transvalvular mean pressure gradient decreased in the entire patient population (from $63.28 \pm 12.9 \mathrm{mmHg}$ to $16.46 \pm 7.9$ $\mathrm{mmHg}$ ), but right outflow tract reintervention rate was greater in Group $1(14.10 \%$ vs $2.3 \%, p=0.04)$. At a mean follow-up interval of $4.9 \pm 33$ years, pulmonary valve insufficiency was severe in $2.47 \%$ of patients in Group 1, whereas it was mild to moderate in $33.3 \%$ of patients in Group 2, the latter having undergone unsuccessful percutaneous balloon valvuloplasty prior to surgery in the vast majority of cases (14/20 vs $6 / 22, p=0.023)$.

Conclusions. Current pulmonary valve sparing techniques are associated with better results, both in terms of survival and freedom from re-intervention at follow-up. Balloon valvuloplasty prior to surgery may worsen operative results, promoting pulmonary insufficiency and therefore should probably be avoided in all patients in whom anatomical characteristics predict failure of percutaneous therapy.

\section{Introduction}

Isolated pulmonary valve (PV) stenosis is a relatively common disorder, accounting for 7-8\% of congenital heart disease (CHD)[1]. It is frequently associated with RASopathies, a group of syndromes caused by germline mutations of the RAS/MAPK pathway[2], such as Noonan syndrome (NS), also showing various degrees of PV leaflet dysplasia.

Surgical repair in the form of transventricular pulmonary valvulotomy was successfully performed in 1948, independently by Sellors[3] and Brock[4]. Surgical treatment of pulmonary stenosis was subsequently challenged in 1982 when Kan reported successful percutaneous balloon valvuloplasty (PBV)[5]. This method of therapy is now applied as the initial procedure of choice[6][7] to patients of all ages, although should be used with caution in cases within case of PV dysplasia[8].

The philosophical attitude of surgical treatment has varied over time, shifting from the original exclusive aim at lowering the pressure into the right ventricle $(R V)$ to the current concomitant focus on preserving 
PV function. In particular, in the last ten years the modified Brom techniques ${ }^{10}$ was applied in order to augment the pulmonary trunk after PV commissurolysis and commissurotomy.

In our center PV sparing techniques have been adopted since 1995. Based on this, in the present study we sought to retrospectively review our 33-yr experience with surgical treatment of PV stenosis, with the aim to highlight the advantages of a PV sparing policy.

\section{Material And Methods}

\section{Demographics}

The study enrolled 123 consecutive patients surgically treated at the Department of Pediatric Cardiology and Cardiac Surgery of the Bambino Gesù Children's Hospital and Research Institute, Rome, Italy, between July 1983 and March 2019, at a mean age and weight of $3 \pm 0.36$ years and $16.6 \pm 1.7 \mathrm{~kg}$, respectively. The Scientific Board of Bambino Gesù Children's Hospital and Research Institute approved the study and waived the need for informed patient consent.

Indications for surgery were a mean transvalvular pressure gradient greater than $50 \mathrm{mmHg}$, or an even a lower gradient, but in the presence of symptoms and/or RV dysfunction.

Genetic syndrome occurred in $61 \%$ of cases. Of these, $90.3 \%$ of patients had NS with genetic prevalence of PTPN11 gene, $5.6 \%$ NS with Multiple Lentigines (also known as LEOPARD syndrome), $1.9 \%$ Wolf syndrome and $1.9 \%$ Down syndrome.

Diagnosis was performed in the earliest era by cardiac catheterization and subsequently by Doppler echocardiography. RV outflow lesions, as also confirmed by surgical inspection, were isolated PV stenosis in $45.5 \%$ of cases, supravalvular and valvular stenosis in $17.9 \%$, and supravalvular stenosis with intact $\mathrm{PV}$ in $36.6 \%$. Average peak gradient was $61.5 \pm 12.9 \mathrm{mmHg}$ and mean $\mathrm{PV}$ annular diameter was $14.44 \mathrm{~mm}$ (IQ range: 12-16) resulting in a mean Boston Z-score of -1.26 (IQ range: -1.97 - -0.25). Variable degree of RV hypertrophy coexisted in $35.1 \%$ of patients. Associated ostium secundum-type atrial septal defect coexisted in $67 \%$ of cases.

Unsuccessful PBV had been performed in $43.9 \%$ of patients prior to surgery. Patients were categorized into 2 groups according to surgical approach. Group 1 consisted of 81 patients treated before 1995 with the exclusive aim of lowering RV pressure; Group 2 consisted of 42 patients treated after the introduction of PV sparing policy at surgery in 1995.

\section{Data Collection and Statistical Analysis}

Clinical evaluation was performed before the intervention, combined with genetic assessment, immediately after surgery and at various intervals during follow-up. 
Cardiac catheterization assessed transpulmonary valve pressure gradient, RV pressure compared to systemic pressure, pulmonary artery trunk pressure and pulmonary regurgitation, pre-operatively, postoperatively and at follow-up. Doppler echocardiography estimated transpulmonary valve pressure gradient, PV annulus diameter and related Boston Z-score, pulmonary regurgitation, RV hypertrophy and dilatation.

Data regarding PBV included procedural effectiveness, post-procedural mean pressure gradient and pulmonary regurgitation. Data regarding surgery included type of intervention, cardiopulmonary by-pass and aortic clamping duration, intra-operative assessment of transpulmonary valve pressure gradient and right ventricular pressure.

Means and frequencies were statistical analyzed by Fisher Exact Test and Chi-square Test respectively. A $p$ value less than 0.05 was considered significant. Kaplan-Meier method was used to calculate survival and freedom from reintervention. Mantel-Cpx Log-Rank test was used for comparison.

Outcomes analyzed were short- and long-term mortality, freedom from reintervention, freedom from PV stenosis and/or regurgitation immediately after intervention and at last follow-up. The study complied with the ethical standards of the Declaration of Helsinki.

\section{Results}

\section{Immediate Results}

Among patients of Group 1, surgical techniques included: transventricular valvulotomy $(n=8)$, open valvulotomy $(n=38)$, valvulotomy associated with transanular patch $(n=5)$, valvulotomy associated with infundibular patch $(n=6)$, valvulectomy $(n=7)$ and valvulectomy associated with transanular patch $(n=17)$.

On the other hand, all patients of Group 2 received PV commissurolysis and commissurotomy associated with augmentation of the pulmonary arterial trunk using an inverted Y-shaped patch (modified Brom technique) (table1). An inverted ipsilon-shaped incision was made on the pulmonary artery trunk extending to both the anterior facing and non-facing sinus (Fig 1). The PV was exposed and inspected, identifying the extent of the commissural fusion. An extensive commissurolysis was performed along with a deep incision of the three commissures advanced into the vessel wall to optimize the central opening of the valve gaining a diameter with a normal Z score as possible (Fig 2).

At this point an ellipsoidal patch of heterologous pericardium was cut and the fixation suture was initiated from the point of divergence of two branches of the ipsilon-shaped incision, proceeding clockwise in the non-facing sinus to the apex of the incision itself.

At this point a longitudinal notch was accurately made on the patch to precisely accommodate the triangle of the pulmonary arterial wall containing the anterior commissure and the suture was continued reaching the height of the contralateral. This point of the technique is crucial for achieving optimal 
reconstruction of the pulmonary sinuses of Valsalva and avoiding any distortion of the pulmonary valve (Fig 3). Fixation of the patch can finally be completed using a second suture started at the apex of the incision and lowered from both sides to rejoin the initial one (Fig 4).

Overall early survival was $96.07 \%$, the early mortality rate was $2.4 \%$. All deaths occurred in Group 1 (3/81 early deaths $=3.76 \%$ early mortality rate), whereas all patients of Group 2 survived.

Surgery was performed on cardiopulmonary bypass in all cases, with a mean bypass time of 70 \pm 4.3 minutes and aortic cross-clamping time of $38.2 \pm 9.6$ minutes. Intraoperative post-repair transpulmonary valve pressure gradient decreased from $63.28 \pm 12.9 \mathrm{mmHg}$ to $19.01 \pm 7 \mathrm{mmHg}$, and pulmonary regurgitation occurred in 13 patients, 2 of which in Group 1 and 11 in Group 2.

\section{Late Results}

At a mean follow-up time of $4.9 \pm 33$ years, overall survival was $98.2 \%$ (long-term mortality: $1.6 \%$ ). Late deaths occurred in 2 patients of Group 1 and 1 patients of Group 2, all with NS and pre-operative severe right ventricle hypertrophy. Overall mortality was then greater for Group $1(4.9 \%)$ than for group $2(3 \%)$, although without a real statistical significance $(p=0.05)$.

RV outflow tract (RVOT) reintervention occurred in 11 out of 78 patients in Group 1 (14.10\% of cases) at a mean interval of 19 years (range: 0.27 - 34 years) from the first surgery ( 5 of whom underwent a third procedure). On the other hand, only 1 out of 42 patients (2.3\%) in Group 2 required RVOT reintervention ( $p$ $=0.04)$. Among patients which did not require reintervention, the PV pressure gradient remained relatively stable after surgery with a mean value of $16.46 \pm 7.9 \mathrm{mmHg}$ on 2D-Echo Doppler. Out of them, 2 patients of Group $2(2.47 \%)$ showed severe valve insufficiency on follow-up, whereas pulmonary incompetence was mild to moderate in $33.3 \%$ of patients in Group 2. Among the latter, those having undergone unsuccessful preoperative PBV showed significantly greater occurrence of postoperative pulmonary incompetence compared to those which did not $(14 / 20$ vs $6 / 22, p=0.023)$.

\section{Discussion}

The improvement of diagnostic tools, surgical procedures and safety at surgery have resulted in a significant reduction of short-term mortality in patients treated for isolated PV stenosis, as the percentage of decease within 30 days from surgery fell from $3.76 \%$ in Group 1 to $0 \%$ in Group 2. Currently, mortality appears to occur only in the long-term, in cases of genetic syndrome and variable degree of preoperative right ventricle hypertrophy/cardiomyopathy.

The introduction of valve sparing policy in 1995 has contributed to the preservation of the RV diastolic function together with a remarkable decrease in re-intervention on the RV outflow tract. Indeed, whilst reoperation was reported in 19 cases of Group 1 (24.35\%), in Group 2 no reoperations were required so far. 
The unsuccessful treatment with PBV for PV stenosis, mainly in patients with RASopathies, has been previously reported by our group ${ }^{11-12}$ in a large multicentric study, where the majority of patients of our cohort needed a second reintervention mainly after a first PBV. Previous Kaplan-Meier curves ${ }^{11}$ have already demonstrated that PV stenosis had a consistently higher risk of earlier intervention when surgical treatment was not considered as first approach. These further data convinced of the ineffectiveness of percutaneous procedures in patients with isolated PV stenosis in the context of some genetic syndromes.

Moreover, the significant rate of postoperative PV insufficiency reported in this study in patients ineffectively treated percutaneously allows to speculate that the damage to the valvular leaflets produced by balloons could have a negative effect on the long-term outcome of surgery and should be probably avoided in patients in whom anatomical characteristics predict failure of percutaneous therapy.

\section{Conclusions}

This is an observational retrospective analysis biased by great changes occurred over time in the surgical treatment of CHD.

Nevertheless, although difficult to compare, the data in this study support the superiority of pulmonary valve sparing policy techniques in patients with isolated PV stenosis. Indeed, commissurolysis and commissurotomy associated with augmentation of the pulmonary artery trunk using an inverted $\mathrm{Y}$ shaped patch (MBT technique), as described, appear to result in a lower short-term mortality and longer freedom from re-intervention.

As long as the current main concern of treatment is to preserve pulmonary valve function, preliminary balloon valvuloplasty should be avoided, particularly in patients with fused valve leaflets in the thickness of the pulmonary arterial wall and valve dysplasia typical of RASopathies, due to high rate of failure and increased probability of post-surgical pulmonary valve incompetence.

\section{Abbreviations}

CHD: congenital heart disease

NS: Noonan Syndrome

PBV: percutaneous balloon valvuloplasty

PV: pulmonary valve

$\mathrm{RV}$ : right ventricle

RVOT: right ventricular outflow tract

\section{Declarations}




\section{ETHICS APPROVAL AND CONSENT TO PARTICIPATE}

This study was conducted in accordance with the Declaration of Helsink.

The Research Ethics Committee of Bambino Gesù Children's Hospital and Research Institute has confirmed that no ethical approval is required due to its characteristic of "case series". Furthermore, the Scientific Board of Bambino Gesù Children's Hospital and Research Institute approved the study. All parents or guardians provided the written informed consent.

\section{CONSENT FOR PUBLICATION}

Not applicable.

\section{CONFLICT OF INTEREST}

The authors report no relationships that could be construed as a conflict of interest.

\section{COMPETING INTERESTS}

The authors declare that they have no competing interests.

\section{FUNDINGS}

No funds have been used for this manuscript.

\section{AUTHORS' CONTRIBUTIONS}

All the authors take responsibility for all aspects of the reliability and freedom from bias of the data presented and their discussed interpretation. All authors participated in collecting data and finally read and approved the final manuscript. In details, S.B.A. wrote the main manuscript text, prepared figures and finally critically revised the manuscript for important intellectual content; M.T. - F.G. reviewed analysis, E.P. A.D.P. G.C. collected results and provided echo imaging. All authors reviewed the final version of this manuscript.

\section{DATA AVAILABILITY STATEMENT}

The data that support the findings of this study are available from the corresponding author upon reasonable request

\section{ACKNOWLEDGMENTS}

The authors wish to thank the subjects whose participation made this study possible.

\section{References}


1. Akagi T. Pulmonic stenosis. In:Crawford MH, Di Marco JP, eds. Cardiology 2002. Orlando, FL: Harcourt Publishers Ltd, 2002:7.14.1-7.14.3.

2. Jhang WK, Choi JH, Lee BH, Kim GH, Yoo Hw. Cardiac manifestations and associations with gene mutations in patients diagnosed with RASopathies. Pediatr Cardiol 2016;37:1539-1547.

3. Sellors TH. The surgery of pulmonary stenosis. Lancet 1948;1:988.

4. Brock RC. Pulmonary valvulotomy for the relief of congenital pulmonary stenosis. Br Med J 1948;1:1121.

5. Kan JS, White RI jr, Mitchell SE, Gardner TJ. Percutaneous ballon valvuloplasty; a new method for treating congenital pulmonary valve stenosis. N Engl J Med 1982;307:540.

6. Cooper R, Ritter S, Golinko R. Percutaneous balloon valvuloplasty: initial and long term results. J Am Coll Cardiol 1982;5:405.

7. Peterson C, Schilthuis JJ, Dodge-Khatami A, Hitchcock JF, Meijboom EJ, Bennik GBWE. Comparative long-term results of surgery versus balloon valvuloplasty for pulmonary valve stenosis in infants and children. Ann Thorac Surg 2003;76:1078-83.

8. Kosetzky ED, Moller JS, Koons ME. Congenital pulmonary stenosis resulting from dysplasia of the valve. Circulation 1969;40:43

9. Harrild DM, Powell AJ, Tran TX. Long-term pulmonary regurgitation following balloon valvuloplasty for pulmonary stenosis: risk factors and relationship to exercice capacity and ventricular volume and function. J Am Coll Cardiol 2010;55:1041-7.

10. Brom, AG . Obstruction of the left ventricular outflow tract. In: Khonsari, S , ed. Cardiac Surgery: Safeguards and Pitfalls in Operative Technique. Rockville, MD: Aspen Publishers; 1988:276-280.

11. Calcagni G, Limongelli G, D'Ambrosio A, Gesualdo F, Digilio MC,Baban A, Albanese SB, Versacci P, De Luca E, Ferrero GB,Baldassarre G, Agnoletti G, Banaudi E, Marek J, Kaski JP, Tuo G, Russo MG, Pacileo G, Milanesi O, Messina D, Marasini M,Cairello F, Formigari R, Brighenti M, Dallapiccola B, TartagliaM, Marino B. Cardiac defects, morbidity and mortality in patients affected by RASopathies.CARNET study results. Int J Cardiol. 2017, 245:92-98

12. Calcagni G, Limongelli G, D'Ambrosio A, Gesualdo F, Digilio MC, Baban A, Albanese SB, Versacci P, De Luca E, Ferrero GB, Baldassarre G, Agnoletti G, Banaudi E, Marek J, Kaski JP, Tuo G, Russo MG, Pacileo G, Milanesi O, Messina D, Marasini M, Cairello F, Formigari R, Brighenti M, Dallapiccola B, Tartaglia M, Marino B. Data on cardiac defects, morbidity and mortality in patients affected by RASopathies. CARNET study results. Data Brief. 2017:16:649-654.

\section{Tables}

Due to technical limitations, table 1 is only available as a download in the Supplemental Files section.

\section{Figures}




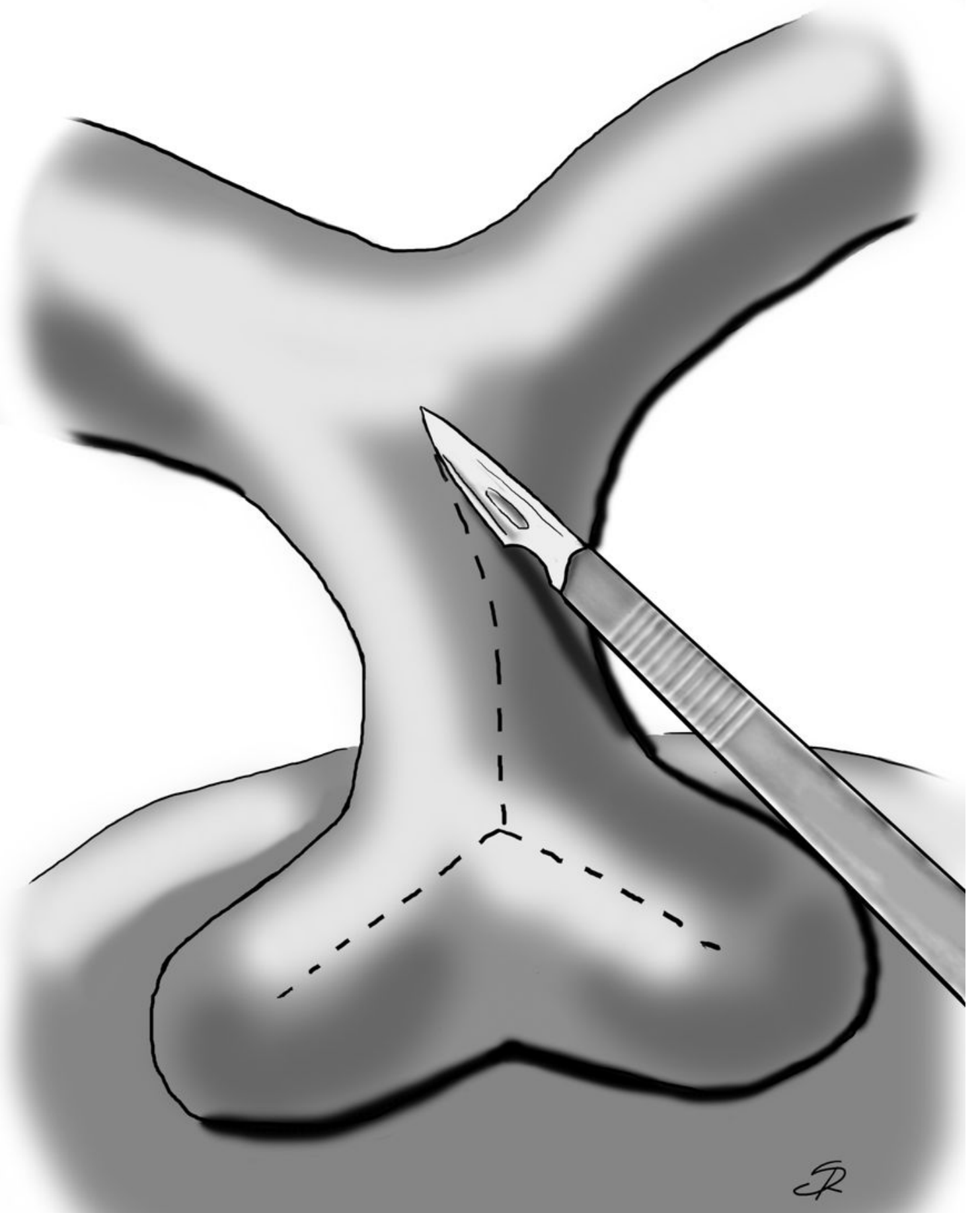

Figure 1

Inverted ipsilon-shaped incision of the pulmonary artery trunk 


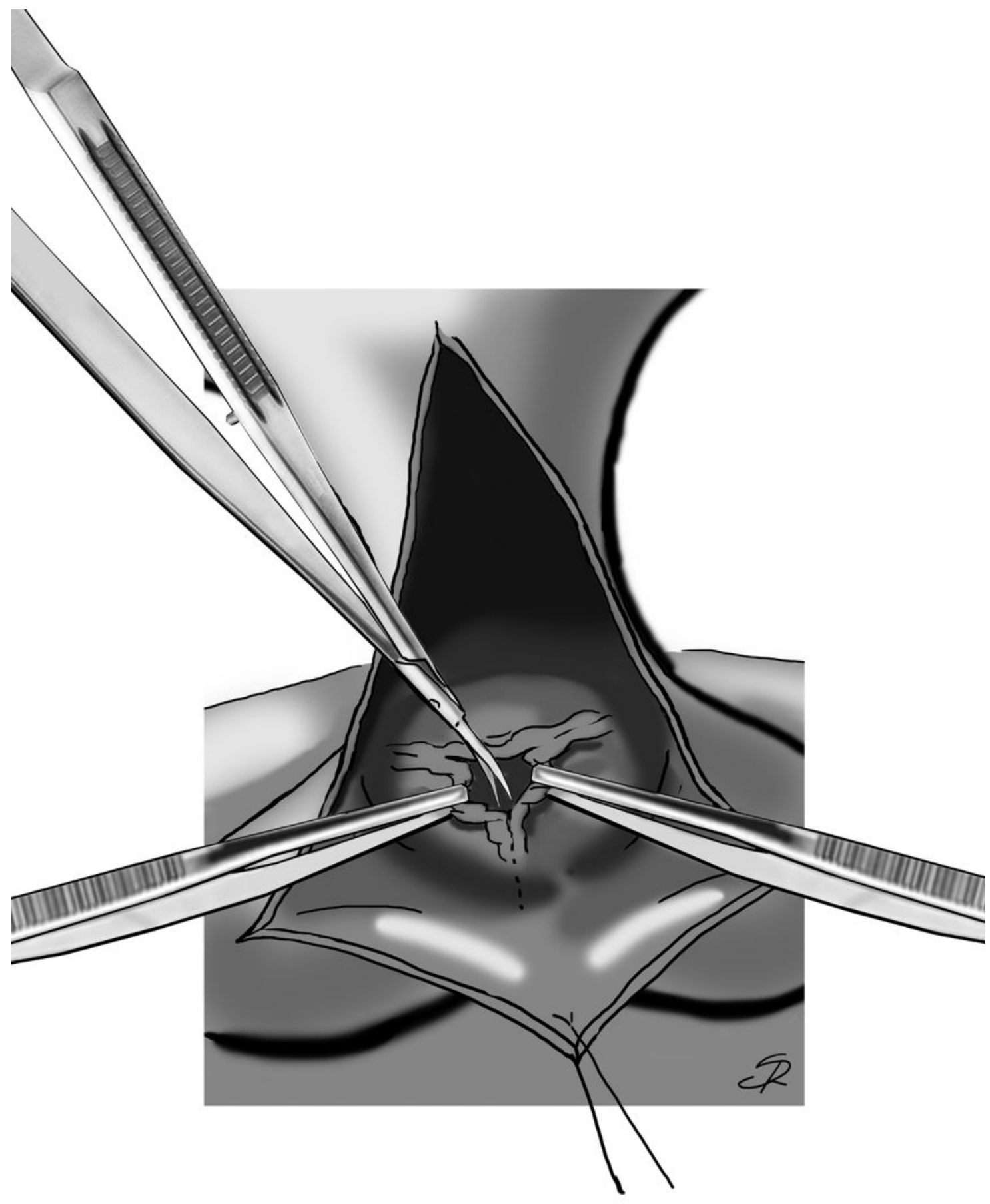

Figure 2

Extensive commissurolysis of the pulmonary valve. 


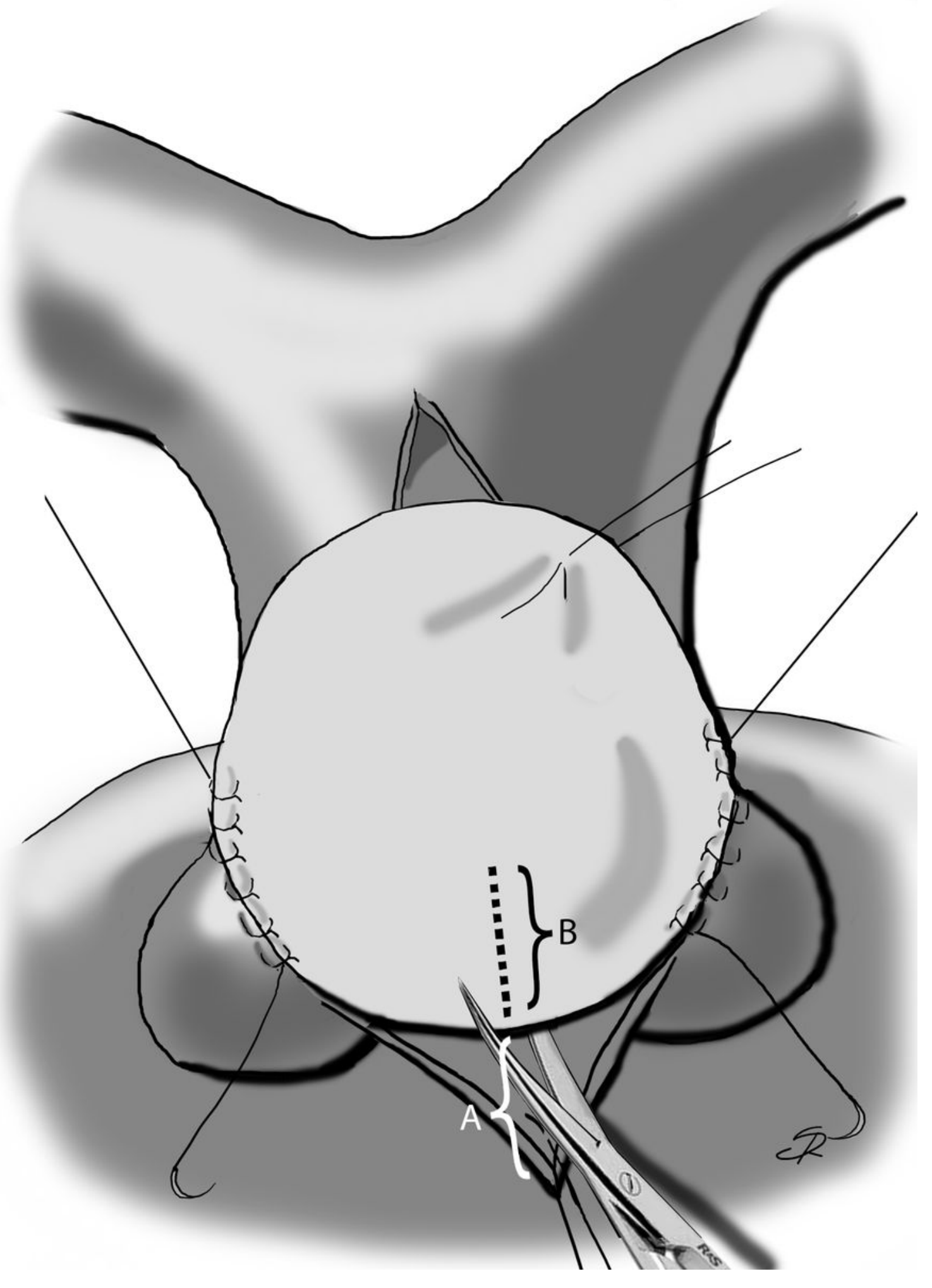

Figure 3

Fixation technique of ellipsoidal patch 


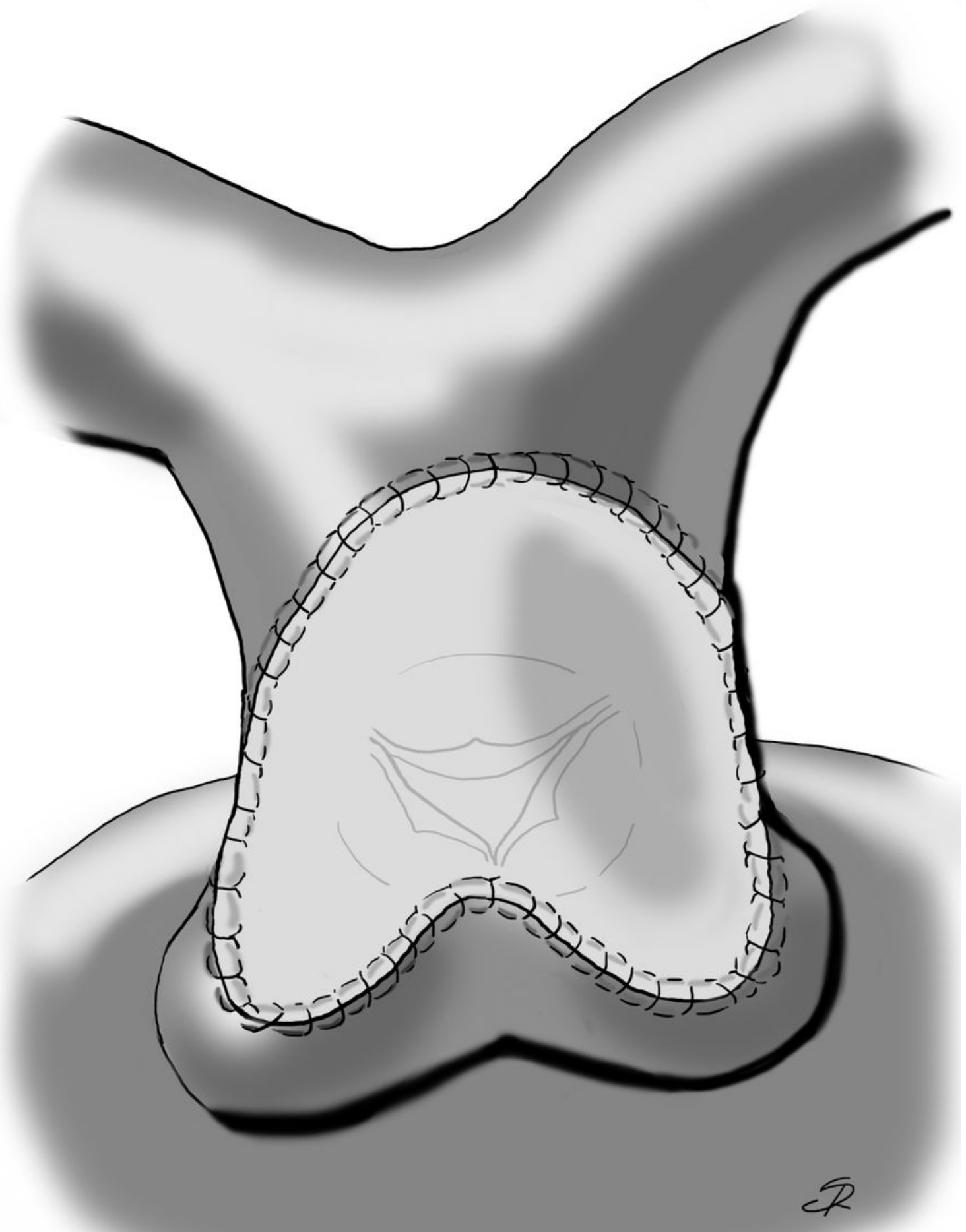

Figure 4

Final result

\section{Supplementary Files}

This is a list of supplementary files associated with this preprint. Click to download. 
- table1.xlsx

Page 13/13 